Proceedings

\title{
Voltammetric Study of the Affinity of Divalent Heavy Metals for Guanine Functionalized Iron Oxide Nanoparticles ${ }^{\dagger}$
}

\author{
Simona Sawan, Khalil Hamze, Ali Youssef, Rayyan Boukarroum, Kamal Bouhadir, Abdelhamid \\ Errachid, Rita Maalouf and Nicole Jaffrezic-Renault \\ 1 Institut des Sciences Analytiques, Université de Lyon, Claude Bernard Lyon 1, UMR 5280, CNRS-5, rue de \\ la Doua, 69100 Villeurbanne, France \\ 2 Department of Sciences, Faculty of Natural and Applied Sciences, Notre Dame University-Louaize, \\ Zouk Mosbeh, Lebanon \\ 3 Department of Chemistry, American University of Beirut, Beirut 11-0236 and Lebanon \\ + Presented at the 7th International Electronic Conference on Sensors and Applications, 15-30 November \\ 2020; Available online: https://ecsa-7.sciforum.net/.
}

Published: 15 November 2020

\begin{abstract}
The smallest concentrations of heavy metal ions can be harmful to both the environment and human health. They are non-biodegradable and can accumulate all along the food chain, thus their onsite monitoring and removal is of great importance. In this work, a novel material based on (3-aminopropyl) triethoxysilane (APTES) coated iron oxide $\left(\mathrm{Fe}_{3} \mathrm{O}_{4}\right)$ nanoparticles functionalized with guanine hydrazide $(\mathrm{GH})$ was elaborated. Fourier transform infrared spectroscopy, energydispersive X-ray analysis and X-ray diffraction were used to control the synthesis and functionalization steps of the nanoparticles. The morphology and particle size were studied by scanning electron microscopy. Spherical nanoparticles with an average diameter of $45 \mathrm{~nm}$ were obtained. A boron-doped diamond electrode coated with GH-APTES-Fe3 $\mathrm{O}_{4}$ nanoparticles was used to evaluate the electrochemical interaction of some divalent heavy metal ions with guanine hydrazide. Adsorption isotherms were investigated electrochemically and it was shown that the adsorption capacity of the nanoparticles towards heavy metals decreased in the following order: $\mathrm{Cu}^{2+}>\mathrm{Pb}^{2+}>\mathrm{Cd}^{2+}$. Moreover, the signals generated by square wave voltammetry exhibited two distinct linear response ranges; the first linear plot lies in the range of 0.209 to $1.03 \mu \mathrm{M}$ with a sensitivity of $171.6 \mu \mathrm{A} / \mu \mathrm{M}$ for $\mathrm{Cu}$ (II), 0.232 to $0.809 \mu \mathrm{M}$ with a sensitivity of $156 \mu \mathrm{A} / \mu \mathrm{M}$ for $\mathrm{Pb}$ (II) and 0.483 to $4.97 \mu \mathrm{M}$ with a sensitivity of $101.4 \mu \mathrm{A} / \mu \mathrm{M}$ for Cd (II). Furthermore, an excellent reproducibility was achieved with relative standard deviation (RSD) values of $4 \%, 5 \%$ and $10 \%$ respectively over five independent measurements.
\end{abstract}

Keywords: Guanine hydrazide; $\mathrm{Fe}_{3} \mathrm{O}_{4}$ nanoparticles; heavy metals; adsorption isotherm; guanineheavy metal interaction 